\title{
Maximal exercise outcomes with a face mask: the effects of gender and age differences on cardiorespiratory responses
}

\author{
Busra Alkan ${ }^{1,2}$ (D) Sevgi Ozalevli ${ }^{3}$ (D) Ozlem Akkoyun Sert ${ }^{2}$ (D)
}

Received: 19 October 2021 / Accepted: 16 November 2021 / Published online: 26 November 2021

(c) The Author(s), under exclusive licence to Royal Academy of Medicine in Ireland 2021

\begin{abstract}
Background Surgical masks have become an important accessory of physical activity in daily life due to the COVID-19 pandemic.

Aims To determine the effects of the surgical mask on respiratory gas exchange parameters, dyspnoea, and hemodynamic responses during maximal exercise in different age groups and gender.

Methods Twenty-six healthy participants between 18 and 65 years (mean 37.35 \pm 15.99 ) performed a maximal exercise test twice randomly, with and without a mask. To determine the respiratory gas exchange parameters (peak oxygen consumption $\left(\mathrm{VO}_{2 \text { peak }}\right)$, minute ventilation $\left(\mathrm{V}_{\mathrm{E}}\right)$, energy expenditure $(\mathrm{EE})$, respiratory rate), and hemodynamic responses, each participant underwent a maximal exercise test with Bruce protocol on the treadmill. The modified Borg scale (MBS) was used to determine the dyspnoea before and after exercise test.

Results Test duration (min), metabolic equivalents (MET), $\mathrm{VO} 2_{\text {peak }} \mathrm{ml} / \mathrm{kg} / \mathrm{min}$, respiratory rate, and peak heart rate $\left(\mathrm{HR}_{\text {peak }}\right)$ of young participants after exercise test with and without a mask were higher than in middle-aged participants $(p<0.01)$. There was no significant difference between males and females in test duration, $\mathrm{VO}_{2 \text { peak }} \mathrm{ml} / \mathrm{kg} / \mathrm{min}, \mathrm{VO}_{2 \text { peak }} \mathrm{ml} / \mathrm{min}, \mathrm{MET}$, $\mathrm{V}_{\mathrm{E}} \mathrm{l} / \mathrm{min}$, respiratory rate, MBS, and EE in masked tests $(p>0.05)$.

Conclusion The surgical mask use affected the maximal exercise capacity of middle-aged participants more than young participants. Although males performed better than females in tests without masks, the decrease in exercise capacity with mask use was greater than in females. Advanced age and male gender may be factors that need more attention during exercise with mask use.
\end{abstract}

Trial registration number and date NCT04498546—02/17/2021.

Keywords Aging $\cdot$ Exercise capacity $\cdot$ Gender $\cdot$ Mask use $\cdot$ Maximal oxygen consumption

Busra Alkan

busra.alkan@karatay.edu.tr

Sevgi Ozalevli

sevgi.ozalevli@deu.edu.tr

Ozlem Akkoyun Sert

ozlem.sert@karatay.edu.tr

1 Institute of Health Sciences, Dokuz Eylul University, Izmir, Turkey

2 Physiotherapy and Rehabilitation Department, School of Health Sciences, KTO Karatay University, Alaaddin Kap St. No:130, 42020, Karatay, Konya, Turkey

3 School of Physical Therapy and Rehabilitation, Dokuz Eylul University, Izmir, Turkey

\section{Introduction}

International organizations have recommended face masks during the coronavirus disease 2019 (COVID-19) pandemic, and they have become mandatory in various countries [1]. While there is a growing range of recommendations for healthcare professionals and the larger population regarding the use of masks, there are no clear guidelines for individuals undertaking exercise and sports activities [2]. It was stated by Shurlock et al. that the use of face masks during exercise might be health-threatening due to hypercapnia and hypoxemia [2]. In light of recent comments in the literature, it has been hypothesized that exercising with a face mask causes $\mathrm{CO}_{2}$ accumulation [3]. Hypercapnic hypoxia, decreased $\mathrm{O}_{2}$, and increased $\mathrm{CO}_{2}$ resulting from exercise with a face mask exponentially increase the heart rate (HR) 
and blood pressure even at low activity levels [4-6]. On the other hand, there is no evidence that the mask reduces the $\mathrm{O}_{2}$ content in the blood [6].

Maximal oxygen consumption $\left(\mathrm{VO}_{2 \max }\right)$ decreases with age due to decreased cardiac output and muscle blood flow [7]. Hence, the factors limiting $\mathrm{VO}_{2 \max }$ are variable between the young and the older people. When gender is investigated among the factors affecting $\mathrm{VO}_{2 \max }$, males typically had higher maximum aerobic capacity due to larger stroke volumes, greater cardiac output during peak exercise, and increased hemoglobin mass [8]. However, females have substrate utilization advantages that preserve both lipids and exogenously supplemented carbohydrates during exercise [9-11]. Also, females are not prone to oxidative stress that occurs during muscle work and generally have a higher threshold for pain and discomfort than males [12, 13].

Face masks specifically designed to restrict airflow have been shown to negatively affect perceived effort during exercise without a beneficial metabolic response [14]. In addition, the number of studies investigated the use of masks during physical activity is small, and they are generally associated with rest or mild physical activities such as walking [15]. However, the evidence for the effect of gender and age factors on the change in pulmonary gas exchange parameters and hemodynamic responses measured at maximal exercise with mask use is unclear. For this reason, our study was planned to determine the effects of surgical masks on exercise capacity according to age and gender factors.

\section{Material and methods}

\section{Participants}

Participants with enough cognitive and physical function and did not have contraindications for exercise tests (unstable angina, acute infections, recent myocardial infarction, severe symptomatic aortic stenosis, uncontrolled symptomatic heart failure, acute myocarditis or pericarditis, acute pulmonary embolus, or pulmonary infarction, suspected or known dissecting aneurysm, etc.) were included. Individuals with diseases that could not be controlled with medication, with a diagnosis of or contact with COVID-19 in the last 3 months, with critical cardiac (unstable angina, arrhythmia, myocardial infarction, etc.), respiratory or neurological disease, and with regular physical activity habits were excluded.

\section{Study protocol}

The medical histories of the participants were recorded. A maximal exercise test on a treadmill (Treadmill $\mathrm{h} / \mathrm{p}$ cosmos $150 / 50$, Germany) was performed twice randomly for each participant, with and without a surgical mask. There was a break of at least $72 \mathrm{~h}$ between the two maximal tests to prevent muscle fatigue. Exercise tests were performed for each person at the same time and at least $1 \mathrm{~h}$ after eating. The Bruce protocol [16] was chosen to determine the exercise capacity of participants with maximal effort. Peak oxygen consumption $\left(\mathrm{VO}_{2 \text { peak }}\right)$, minute ventilation $(\mathrm{VE})$, and energy expenditure (EE) were measured and calculated directly with a gas analyzer (Cosmed Fitmate Med, Italy). $\mathrm{VO}_{2 \text { peak }}$ was measured at maximal exercise. In masked tests, the gas analyzer mask was placed over the surgical mask. Participants' saturation of peripheral oxygen $\left(\mathrm{SpO}_{2}\right)$, HR, systolic blood pressure (SBP), and diastolic blood pressure (DBP) were recorded at rest, after exertion, and during recovery. The participants were not informed about the results they obtained during the test to overcome the anticipation bias.

\section{Statistical analysis}

The $\mathrm{VO}_{2 \text { peak }}$ difference according to age in Jenkins et al. was considered [17] to determine the sample size. Using the G Power 3.1.9.2 programme, the number of participants required to be included was determined as 13 for each group and 26 participants in total (with 90\% statistical power). The statistical analyses were performed using SPSS 25.0 for Windows. Kolmogorov-Smirnov test was used to analyze the normality of the data. In the comparison between groups, if data were normally distributed, the $t$-test was used in independent groups and the Mann-Whitney $U$ test was used for non-normal distribution. In the intragroup comparison, if data were normally distributed, paired-sample $t$-test was used, and the Wilcoxon signed-rank test was used for non-normal distribution [18]. The significance level was determined at a $95 \%$ confidence interval $(p<0.05)$.

\section{Results}

Twenty-six participants were included in the study and divided into two groups: $18-25$ years $(n=13$, mean age $22.00 \pm 1.91)$ and $45-64$ years $(n=13$, age $52.69 \pm 4.38)$. Also, participants were divided into two groups as males ( $n=11$, mean age $38.64 \pm 16.10$ years) and females $(n=15$, mean age $36.40 \pm 16.41$ years). Group characteristics by age and gender are shown in Table 1. All participants completed the maximal exercise test with and without a mask with no discomfort.

\section{Effects of age differences on maximal exercise cardiorespiratory responses}

The maximal exercise cardiorespiratory responses of individuals with age and gender differences are shown in Table 2. 
Table 1 Baseline characteristics of the participants according to gender and age differences*

\begin{tabular}{lccccc}
\hline & $\begin{array}{l}\text { Total } \\
(n=26) \\
\text { Mean } \pm \mathrm{SD}\end{array}$ & $\begin{array}{l}18-25 \text { years } \\
(n=13) \\
\text { Mean } \pm \mathrm{SD}\end{array}$ & $\begin{array}{l}\text { 45-64 years } \\
(n=13) \\
\text { Mean } \pm \mathrm{SD}\end{array}$ & $\begin{array}{l}\text { Males } \\
(n=11) \\
\text { Mean } \pm \mathrm{SD}\end{array}$ & $\begin{array}{l}\text { Females } \\
(n=15) \\
\text { Mean } \pm \mathrm{SD}\end{array}$ \\
\hline Age, y & $37.35 \pm 15.99$ & $22.00 \pm 1.91$ & $52.69 \pm 4.38$ & $38.64 \pm 16.10$ & $36.40 \pm 16.41$ \\
Height, $\mathrm{m}$ & $1.71 \pm 0.07$ & $1.73 \pm 0.08$ & $1.68 \pm 0.06$ & $1.76 \pm 0.06$ & $1.67 \pm 0.06$ \\
Weight, kg & $76.36 \pm 14.45$ & $68.53 \pm 11.37$ & $84.19 \pm 13.15$ & $82.77 \pm 13.76$ & $71.66 \pm 13.48$ \\
BMI, kg/m ${ }^{2}$ & $26.10 \pm 4.96$ & $22.54 \pm 2.39$ & $29.66 \pm 4.25$ & $26.59 \pm 4.12$ & $25.73 \pm 5.61$ \\
HR, bpm & $88.69 \pm 10.93$ & $91.62 \pm 12.59$ & $85.77 \pm 8.47$ & $88.55 \pm 13.53$ & $88.80 \pm 9.08$ \\
SBP, $\mathrm{mmHg}$ & $113.85 \pm 9.82$ & $110.00 \pm 8.41$ & $117.69 \pm 9.92$ & $114.55 \pm 11.50$ & $113.33 \pm 8.79$ \\
DBP, $\mathrm{mmHg}$ & $76.73 \pm 9.89$ & $65.00 \pm 6.12$ & $81.54 \pm 7.46$ & $76.36 \pm 9.24$ & $77.00 \pm 10.65$ \\
\hline
\end{tabular}

$B M I$ body mass index, $S B P$ systolic blood pressure, $D B P$ diastolic blood pressure, $H R$ heart rate, $S p O 2$ peripheral oxygen saturation, $M B S$ modified Borg Scale

*Values are presented as mean $\pm \mathrm{SD}$
In the intragroup comparison of young and middle-aged participants, met $(p<0.01), \mathrm{VO}_{2 \text { peak }} \mathrm{ml} / \mathrm{kg} / \mathrm{min}(p<0.01), \mathrm{V}_{\mathrm{E}} \mathrm{l} /$ $\min (\mathrm{p}<0.01)$, and EE kcal/hour $(p<0.01)$ were found to be significantly lower in masked tests.

In intergroup comparison, test duration (min), metabolic equivalent (MET), $\mathrm{VO}_{2 \text { peak }} \mathrm{ml} / \mathrm{kg} / \mathrm{min}$, respiratory rate, and $\mathrm{HR}_{\text {peak }}$ of young participants after maximal exercise with and without mask were higher than in middle-aged participants $(p<0.01)$. In the masked test in the young group, there was a mean of $0.33 \pm 0.56(p>0.05)$ minute decrease in total exercise time compared to the unmasked test. This decreases a mean of $1.17 \pm 1.96(p>0.05)$ minutes in the middle-aged group. A difference in the mean of $4.33 \pm 4.42 \mathrm{ml} / \mathrm{kg} / \mathrm{min}$ $(p<0.01)$ was found between the mean $\mathrm{VO}_{2 \text { peak }}$ measured in the unmasked test and masked test in middle-aged participants. This difference was a mean of $4.52 \pm 5.11 \mathrm{ml} / \mathrm{kg} /$ $\min (p<0.01)$ in young participants. There was no difference between the two masked and unmasked age groups in the $\mathrm{VO}_{2 \text { peak }} \mathrm{ml} / \mathrm{min}$, minute ventilation $\left(\mathrm{V}_{\mathrm{E}}\right)$, and energy expenditure (EE) measured at maximal exercise $(p>0.05)$.

\section{Effects of gender differences on maximal exercise cardiorespiratory responses}

In the intragroup comparison of males and females, met (males $p<0.01$, females $p=0.031$ ), $\mathrm{VO}_{2 \text { peak }} \mathrm{ml} / \mathrm{kg} / \mathrm{min}$

Table 2 Effects of age differences on maximal exercise cardiorespiratory responses

\begin{tabular}{|c|c|c|c|c|c|c|c|}
\hline & & $\begin{array}{l}18-25 \text { years } \\
\text { Mean } \pm S D\end{array}$ & $\begin{array}{l}45-64 \text { years } \\
\text { Mean } \pm S D\end{array}$ & $p$ age & $\begin{array}{l}\text { Males } \\
\text { Mean } \pm \text { SD }\end{array}$ & $\begin{array}{l}\text { Females } \\
\text { Mean } \pm S D\end{array}$ & $p$ gender \\
\hline \multirow[t]{2}{*}{ Test Duration, min } & Unmasked & $10.17 \pm 1.13$ & $8.05 \pm 1.88$ & $<0.01 *$ & $9.75 \pm 2.27$ & $8.64 \pm 1.40$ & 0.113 \\
\hline & Masked & $9.83 \pm 1.07$ & $6.88 \pm 1.92$ & $<0.01 *$ & $8.50 \pm 2.58 \dagger$ & $8.25 \pm 1.85$ & 0.776 \\
\hline \multirow[t]{2}{*}{ MET } & Unmasked & $8.82 \pm 1.71$ & $6.35 \pm 1.10$ & $<0.01 *$ & $8.70 \pm 2.05$ & $6.77 \pm 1.29$ & $0.015^{*}$ \\
\hline & Masked & $7.52 \pm 1.39 \dagger$ & $5.11 \pm 1.19 \dagger$ & $<0.01 *$ & $6.37 \pm 2.29 \dagger$ & $6.28 \pm 1.36 \dagger$ & 0.906 \\
\hline \multirow[t]{2}{*}{$\mathrm{VO}_{2 \text { peak, }} \mathrm{ml} / \mathrm{kg} / \mathrm{min}$} & Unmasked & $30.09 \pm 6.02$ & $22.26 \pm 3.80$ & $<0.01^{*}$ & $30.47 \pm 7.22$ & $23.73 \pm 451$ & $0.015^{*}$ \\
\hline & Masked & $26.37 \pm 4.90 \dagger$ & $17.92 \pm 4.13 \dagger$ & $<0.01 *$ & $22.35 \pm 799 \dagger$ & $22.00 \pm 4.78 \dagger$ & 0.889 \\
\hline \multirow[t]{2}{*}{$\mathrm{VO}_{2 \text { peak, }} \mathrm{ml} / \mathrm{dk}$} & Unmasked & $2140.15 \pm 652.73$ & $1879.00 \pm 464.27$ & 0.251 & $2486.36 \pm 548.45$ & $1659.93 \pm 239.08$ & $<0.01^{*}$ \\
\hline & Masked & $1795 \pm 458.43 \dagger$ & $1509.61 \pm 386.09 \dagger$ & 0.098 & $1803.73 \pm 556.86 \dagger$ & $1542.07 \pm 305.68 \dagger$ & 0.137 \\
\hline \multirow[t]{2}{*}{$\mathrm{V}_{\mathrm{E}}, 1 / \mathrm{min}$} & Unmasked & $78.42 \pm 20.43$ & $66.21 \pm 20.75$ & 0.144 & $86.00 \pm 23.31$ & $62.28 \pm 12.37$ & $<0.01^{*}$ \\
\hline & Masked & $61.93 \pm 14.88 \dagger$ & $50.63 \pm 14.32 \dagger$ & 0.060 & $57.97 \pm 20.96 \dagger$ & $55.05 \pm 10.37 \dagger$ & 0.643 \\
\hline \multirow[t]{2}{*}{ Respiratory Rate } & Unmasked & $44.54 \pm 7.14$ & $34.92 \pm 6.38$ & $<0.01 *$ & $39.55 \pm 6.66$ & $39.87 \pm 9.48$ & 0.924 \\
\hline & Masked & $42.84 \pm 7.96$ & $32.76 \pm 7.39$ & $<0.01 *$ & $35.45 \pm 10.29 \dagger$ & $39.53 \pm 8.08$ & 0.268 \\
\hline \multirow[t]{2}{*}{$\mathrm{HR}_{\text {peak }}, \mathrm{bpm}$} & Unmasked & $185.54 \pm 8.84$ & $157.92 \pm 13.57$ & $<0.01 *$ & $169.64 \pm 20.76$ & $173.27 \pm 16.29$ & 0.622 \\
\hline & Masked & $179.38 \pm 11.66$ & $153.76 \pm 17.41$ & $<0.01 *$ & $157.09 \pm 22.61 \dagger$ & $173.53 \pm 13.91$ & $0.049^{*}$ \\
\hline \multirow[t]{2}{*}{ EE, kcal/hour } & Unmasked & $642.15 \pm 195.87$ & $563.69 \pm 139.16$ & 0.251 & $746.00 \pm 164.50$ & $498.00 \pm 71.65$ & $<0.01 *$ \\
\hline & Masked & $538.69 \pm 137.53 \dagger$ & $452.69 \pm 115.72 \dagger$ & 0.097 & $541.00 \pm 167.10 \dagger$ & $462.47 \pm 91.57 \dagger$ & 0.137 \\
\hline
\end{tabular}

$V O_{2 \text { peak }}$ peak oxygen consumption, $V_{E}$ minute ventilation, $E E$ energy expenditure, $H R$ heart rate, $M E T$ metabolic equivalent

*Independent Student $t$ test and Mann-Whitney $U$ test, $p<0.05$ (between-groups analysis)

${ }^{\dagger}$ Paired Student $t$ test and Wilcoxon Signed-rank test, $p<0.05$ (within-groups analysis) 
(males $p<0.01$, females $p=0.032), \mathrm{V}_{\mathrm{E}} 1 / \mathrm{min}(p<0.01)$, and $\mathrm{EE} \mathrm{kcal} /$ hour (males $p<0.01$, females $p=0.029$ ) were found to be significantly lower in masked tests. In intergroup comparison, cardiorespiratory responses compared by gender, the MET $(p=0.015), \mathrm{VO}_{2 \text { peak }} \mathrm{ml} / \mathrm{kg} / \mathrm{min}(p=0.015)$, $\mathrm{VO}_{2 \text { peak }} \mathrm{ml} / \mathrm{min}(p<0.01)$, EE kcal/hour $(p<0.01)$, and $\mathrm{V}_{\mathrm{E}}$ $1 / \mathrm{min}(p<0.01)$, measured in the unmasked test in males, were higher than females. There was no difference between males and females in the respiratory rate, $\mathrm{HR}_{\text {peak }}$, and test duration in the unmasked tests $(p>0.05)$.

Among masked measurements, $\mathrm{HR}_{\text {peak }}$ was higher in females than males $(p=0.049)$. There were no differences in masked tests in test duration, $\mathrm{VO}_{2 \text { peak }} \mathrm{ml} / \mathrm{kg} / \mathrm{min}, \mathrm{VO}_{2 \text { peak }}$ $\mathrm{ml} / \mathrm{min}, \mathrm{MET}, \mathrm{V}_{\mathrm{E}} 1 / \mathrm{min}$, respiratory rate, and EE between males and females $(p>0.05)$.

\section{Effects of age differences on maximal exercise hemodynamic responses and dyspnoea}

There were no differences between young and middle-aged participants in SBP, and MBS in masked and unmasked measurements at rest $(p>0.05)$. Among the measurements at rest, DBP was lower $(p=0.017)$ and $\mathrm{SpO}_{2}(p=0.011)$ was higher in the young participants than middle-aged participants in the unmasked measurement. But there were no differences between the two groups in DBP and $\mathrm{SpO}_{2}$ in masked measurement at rest $(p>0.05)$. HR at rest in masked measurement was higher in young participants $(p=0.019)$.

Regarding the hemodynamic responses measured immediately after maximal exercise, the SBP and DBP were higher, and HR was lower in middle-aged participants in the unmasked test $(p<0.01)$. The HR and DBP immediately after test with mask was higher in middle-aged participants $(p<0.01)$. There were no differences between the two groups in terms of $\mathrm{SpO}_{2}$ and MBS immediately after unmasked and masked tests $(p>0.05)$.

In the unmasked measurements during recovery, HR $(p=0.013)$ was higher, and DBP $(p<0.01)$ was lower in young participants. There were no differences in terms of $\mathrm{SBP}, \mathrm{SpO}_{2}$, and MBS between the two groups in unmasked recovery measurements $(p>0.05)$. Among the masked measurements during recovery, $\operatorname{SBP}(p=0.012)$ and DBP $(p=<0.01)$ were higher, and HR $(p=0.019)$ was lower in middle-aged participants.

Delta $(\Delta)$ values of DBP and MBS, which were compared to determine the change in hemodynamic responses at rest and immediately after exercise, were not different in the young and middle-aged groups in the unmasked test $(p>0.05) . \Delta \mathrm{SBP}(p<0.01)$ was greater and $\Delta \mathrm{HR}(p<0.01)$ was lower in middle-aged participants in unmasked test. $\Delta \mathrm{DBP}(p=0.037)$ and $\Delta \mathrm{HR}(p=0.032)$ were greater in young participants in masked test.

\section{Effects of gender differences on maximal exercise hemodynamic responses and dyspnoea}

SBP, DBP, HR, MBS, and delta values measured at rest, after exercise and recovery, were not different between males and females in masked and unmasked tests $(p>0.05)$. $\mathrm{SpO}_{2}$ measured at rest was statistically higher in females than males in unmasked $(p=0.016)$ and masked $(p<0.01)$ measurements. The $\mathrm{SpO}_{2}$ measured after exercise and during recovery was higher in females in unmasked measurements $(p<0.01)$.

\section{Discussion}

The effects of mask use on exercise capacity and respiratory gas exchange parameters related to age and gender factors were investigated in our study (Table 3 ). We concluded that older age and male gender had a greater negative effect on exercise capacity with mask use.

The recommended use of masks with the COVID-19 pandemic to prevent the risk of contamination raises concerns regarding negative effects, such as increased work of breathing, changes in respiratory gas exchange associated with re-breathing of exhaled carbon dioxide, and reduced ventilation during physical activity $[19,20]$. The responses of older and young adults to exercise using masks may be different with some changes with aging. It has been stated that there is a need for studies on cardiopulmonary responses of face masks during exercise in the elderly population [19]. In line this need in the literature, and the increasing use of masks in daily life, the effects of mask use on exercise capacity according to age differences were examined in this study. With masks, a greater reduction in total exercise time was observed in middle-aged participants than in young participants. This finding showed that masks in middle-aged individuals negatively affect exercise duration compared to young participants. After using a mask, $\mathrm{VO}_{2 \text { peak }}(\mathrm{ml}(\mathrm{kg} /$ $\mathrm{min}$ ) decreased more in young participants. This finding was since young people had a higher $\mathrm{VO}_{2 \text { peak }}(\mathrm{ml}(\mathrm{kg} / \mathrm{min})$ in the unmasked test. However, there was no difference between the middle-aged and young groups in masked and unmasked tests in terms of $\mathrm{VO}_{2 \text { peak }}(\mathrm{ml} / \mathrm{min})$. Considering both results, the reason for the lower $\mathrm{VO}_{2}$ in middle-aged individuals may be related to body weight. The younger group's lower body mass index (BMI) creates a response close to maximal oxygen consumption. As a result, it was concluded that BMI had a greater effect on the determination of exercise capacity rather than age.

Gender is an important factor to consider in the evaluation of exercise performance. Males typically have a higher maximal aerobic capacity due to their larger stroke volume, higher cardiac output, and increased hemoglobin mass 
Table 3 Effects of age and gender differences on maximal exercise hemodynamic responses and dyspnoea

\begin{tabular}{|c|c|c|c|c|c|c|c|}
\hline & & $\begin{array}{l}18-25 \text { years } \\
\text { Mean } \pm S D\end{array}$ & $\begin{array}{l}45-64 \text { years } \\
\text { Mean } \pm \text { SD }\end{array}$ & $P$ age & $\begin{array}{l}\text { Male } \\
\text { Mean } \pm \text { SD }\end{array}$ & $\begin{array}{l}\text { Female } \\
\text { Mean } \pm \text { SD }\end{array}$ & $P$ gender \\
\hline \multicolumn{8}{|l|}{ Rest } \\
\hline \multirow[t]{2}{*}{$\mathrm{SBP}, \mathrm{mmHg}$} & Unmasked & $110.00 \pm 8.42$ & $117.69 \pm 9.92$ & 0.076 & $114.55 \pm 11.50$ & $113.33 \pm 8.80$ & 0.707 \\
\hline & Masked & $104.62 \pm 10.50$ & $114.62 \pm 14.50$ & 0.064 & $114.09 \pm 14.29$ & $106.33 \pm 12.17$ & 0.149 \\
\hline \multirow[t]{2}{*}{ DBP, $\mathrm{mmHg}$} & Unmasked & $71.92 \pm 9.90$ & $81.54 \pm 7.47$ & $0.017 *$ & $76.36 \pm 9.24$ & $77.00 \pm 10.66$ & 0.650 \\
\hline & Masked & $70.77 \pm 10.38$ & $79.23 \pm 10.96$ & 0.089 & $76.82 \pm 9.56$ & $73.67 \pm 12.60$ & 0.435 \\
\hline \multirow[t]{2}{*}{$\mathrm{HR}, \mathrm{bpm}$} & Unmasked & $91.62 \pm 12.59$ & $85.77 \pm 8.48$ & 0.178 & $88.55 \pm 13.54$ & $88.80 \pm 9.08$ & 0.955 \\
\hline & Masked & $95.77 \pm 13.83$ & $84.92 \pm 5.63$ & $0.019^{*}$ & $88.18 \pm 10.57$ & $91.93 \pm 12.63$ & 0.432 \\
\hline \multirow[t]{2}{*}{$\mathrm{SpO}_{2} \%$} & Unmasked & $97.92 \pm 0.76$ & $96.46 \pm 1.66$ & $0.011^{*}$ & $96.36 \pm 1.63$ & $97.80 \pm 1.01$ & $0.016^{*}$ \\
\hline & Masked & $97.08 \pm 1.19$ & $96.85 \pm 1.07$ & 0.766 & $96.27 \pm 0.47$ & $97.47 \pm 1.19$ & $<0.01 *$ \\
\hline \multirow[t]{2}{*}{ MBS } & Unmasked & $0.27 \pm 0.39$ & $0.54 \pm 0.95$ & 0.791 & $0.59 \pm 1.00$ & $0.27 \pm 0.42$ & 0.532 \\
\hline & Masked & $0.42 \pm 0.64$ & $0.31 \pm 0.83$ & 0.362 & $0.41 \pm 0.92$ & $0.33 \pm 0.59$ & 0.824 \\
\hline \multicolumn{8}{|c|}{ Immediately after test } \\
\hline \multirow[t]{2}{*}{$\mathrm{SBP}, \mathrm{mmHg}$} & Unmasked & $130.00 \pm 16.20$ & $155.77 \pm 20.80$ & $<0.01 *$ & $143.18 \pm 20.03$ & $142.67 \pm 24.85$ & 0.955 \\
\hline & Masked & $133.85 \pm 14.46$ & $152.69 \pm 25.22$ & 0.062 & $149.09 \pm 21.19$ & $139.00 \pm 22,85$ & 0.164 \\
\hline \multirow[t]{2}{*}{$\mathrm{DBP}, \mathrm{mmHg}$} & Unmasked & $65.00 \pm 6.12$ & $79.62 \pm 9.23$ & $<0.01 *$ & $71.36 \pm 9.77$ & $73.00 \pm 11.62$ & 0.708 \\
\hline & Masked & $66.15 \pm 4.63$ & $80.00 \pm 9.13$ & $<0.01^{*}$ & $74.55 \pm 10.11$ & $72.00 \pm 10.14$ & 0.401 \\
\hline \multirow[t]{2}{*}{ HR, bpm } & Unmasked & $168.46 \pm 11.59$ & $144.85 \pm 12.14$ & $<0.01 *$ & $157.45 \pm 18.65$ & $156.07 \pm 15.85$ & 0.839 \\
\hline & Masked & $95.77 \pm 13.83$ & $139.00 \pm 18.04$ & $<0.01 *$ & $147.00 \pm 27.81$ & $155.80 \pm 13.04$ & 0.348 \\
\hline \multirow[t]{2}{*}{$\mathrm{SpO}_{2} \%$} & Unmasked & $97.00 \pm 1.87$ & $97.15 \pm 0.69$ & 0.645 & $96.18 \pm 1.54$ & $97.73 \pm 0.80$ & $<0.01 *$ \\
\hline & Masked & $96.31 \pm 2.78$ & $97.15 \pm 1.21$ & 0.749 & $95.82 \pm 2.36$ & $97.40 \pm 1.76$ & $0.014 *$ \\
\hline \multirow[t]{2}{*}{ MBS } & Unmasked & $5.23 \pm 1.74$ & $5.38 \pm 2.29$ & 0.855 & $5.00 \pm 1.84$ & $5.53 \pm 2.13$ & 0.510 \\
\hline & Masked & $6.15 \pm 1.68$ & $5.38 \pm 2.36$ & 0.348 & $5.27 \pm 2.05$ & $6.13 \pm 2.03$ & 0.280 \\
\hline \multicolumn{8}{|l|}{ Recovery } \\
\hline \multirow[t]{2}{*}{$\mathrm{SBP}, \mathrm{mmHg}$} & Unmasked & $108.08 \pm 8.05$ & $113.46 \pm 9.22$ & 0.103 & $113.18 \pm 9.56$ & $109.00 \pm 8.28$ & 0.145 \\
\hline & Masked & $105.38 \pm 5.58$ & $114.62 \pm 9.89$ & $0.012^{*}$ & $110.45 \pm 8.20$ & $109.67 \pm 10.08$ & 0.680 \\
\hline \multirow[t]{2}{*}{$\mathrm{DBP}, \mathrm{mmHg}$} & Unmasked & $69.23 \pm 7.87$ & $80.00 \pm 6.77$ & $<0.01^{*}$ & $73.64 \pm 7.78$ & $75.33 \pm 10.08$ & 0.646 \\
\hline & Masked & $71.15 \pm 7.12$ & $80.77 \pm 9.09$ & $<0.01 *$ & $74.09 \pm 6.64$ & $77.33 \pm 11.00$ & 0.743 \\
\hline \multirow[t]{2}{*}{$\mathrm{HR}, \mathrm{bpm}$} & Unmasked & $112.00 \pm 10.65$ & $101.85 \pm 8.48$ & $0.013^{*}$ & $109.91 \pm 11.19$ & $104.73 \pm 10.25$ & 0.233 \\
\hline & Masked & $111.15 \pm 12.68$ & $98.46 \pm 13.14$ & $0.019^{*}$ & $100.91 \pm 15.66$ & $107.67 \pm 12.84$ & 0.239 \\
\hline \multirow[t]{2}{*}{$\mathrm{SpO}_{2} \%$} & Unmasked & $97.23 \pm 1.09$ & $96.46 \pm 1.27$ & 0.124 & $95.91 \pm 1.04$ & $97.53 \pm 0.83$ & $<0.01 *$ \\
\hline & Masked & $97.31 \pm 1.11$ & $96.77 \pm 1.36$ & 0.355 & $96.64 \pm 0.67$ & $97.33 \pm 1.50$ & 0.073 \\
\hline \multirow[t]{2}{*}{ MBS } & Unmasked & $0.88 \pm 1.19$ & $0.73 \pm 0.93$ & 0.990 & $0.82 \pm 1.08$ & $0.80 \pm 1.07$ & 0.933 \\
\hline & Masked & $1.08 \pm 1.30$ & $0.77 \pm 1.17$ & 0.483 & $0.68 \pm 1.19$ & $1.10 \pm 1.26$ & 0.394 \\
\hline \multicolumn{8}{|l|}{ Delta } \\
\hline \multirow[t]{2}{*}{$\Delta \mathrm{SBP}, \mathrm{mmHg}$} & Unmasked & $20.00 \pm 15.00$ & $38.08 \pm 14.22$ & $<0.01 *$ & $28.64 \pm 15.02$ & $29.33 \pm 18.89$ & 0.920 \\
\hline & Masked & $29.23 \pm 10.38$ & $38.08 \pm 18.99$ & 0.208 & $35.00 \pm 13.60$ & $32.67 \pm 17,41$ & 0.651 \\
\hline \multirow[t]{2}{*}{$\Delta \mathrm{DBP}, \mathrm{mmHg}$} & Unmasked & $-6.92 \pm 5.22$ & $-1.92 \pm 9.25$ & 0.103 & $-5.00 \pm 8.66$ & $-4.00 \pm 7.37$ & 0.754 \\
\hline & Masked & $-4.62 \pm 9.00$ & $0.77 \pm 8.38$ & $0.037 *$ & $-2.27 \pm 8.47$ & $-1.67 \pm 9.57$ & 0.915 \\
\hline \multirow[t]{2}{*}{$\Delta \mathrm{HR}, \mathrm{bpm}$} & Unmasked & $76.85 \pm 13.99$ & $59.08 \pm 17.85$ & $<0.01 *$ & $68.91 \pm 22.17$ & $67.27 \pm 15.34$ & 0.825 \\
\hline & Masked & $69.38 \pm 16.04$ & $54.08 \pm 18.19$ & $0.032 *$ & $58.82 \pm 24.37$ & $63.87 \pm 13.32$ & 0.504 \\
\hline \multirow[t]{2}{*}{$\Delta \mathrm{SpO}_{2} \%$} & Unmasked & $-0.92 \pm 1.93$ & $0.69 \pm 1.32$ & $0.029 *$ & $-0.18 \pm 2.60$ & $-0.07 \pm 1.03$ & 0.709 \\
\hline & Masked & $-0.77 \pm 2.28$ & $0.31 \pm 1.84$ & 0.140 & $-0.45 \pm 2.30$ & $-0.07 \pm 2.02$ & 0.683 \\
\hline$\triangle \mathrm{MBS}$ & Unmasked & $4.96 \pm 1.55$ & $4.85 \pm 2.73$ & 0.896 & $4.41 \pm 2.21$ & $5.27 \pm 2.15$ & 0.330 \\
\hline & Masked & $5.73 \pm 1.56$ & $5.08 \pm 2.60$ & 0.776 & $4.86 \pm 2.12$ & $5.80 \pm 2.12$ & 0.250 \\
\hline
\end{tabular}

$S B P$ systolic blood pressure, $D B P$ diastolic blood pressure, $H R$ heart rate, $\mathrm{SpO}_{2}$ peripheral oxygen saturation, $M B S$ Modified Borg Scale *Independent Student $t$ test and Mann-Whitney $U$ test, $p<0.05$ (between-groups analysis) 
during peak exercise [11]. When the test results of males and females were compared, the test duration, MET, and $\mathrm{VO}_{2 \text { peak }}$ were higher in males than females in unmasked tests. However, it can be concluded that this difference disappeared when the mask was used. In other words, in accordance with the literature, while males had better exercise capacity than females during tests without masks, the decrease in exercise capacity with mask use was found to be higher than females. In addition, the minute ventilation with mask use in males decreased more than females. Although it was stated in the study findings that there was no difference between males and females in the dyspnoea level, the negative effects on objectively measured respiratory gas exchange parameters were higher in males. It has been reported in the literature that females are less prone to oxidative stress during muscle work than males, and pain tolerance is better in females than in males $[12,13]$. Based on these findings, the use of masks during maximal effort puts more pressure on males than females and reduces minute ventilation and oxygen consumption.

Regarding the change of oxygen saturation with the use of masks are contradictory in the literature. Although there are studies show that mask use did not change oxygen saturation [21,22], one study reported that oxygen saturation decreased during exercise at $65 \%$ of the maximal workload [23]. In our study, in which exercises were performed at maximum workload, among the hemodynamic responses, $\mathrm{SpO}_{2}$ was found to be statistically different according to age and gender groups. Consistent with the literature, it was an expected result that the $\mathrm{SpO}_{2}$ was higher in young participants and this phenomenon did not change with the use of masks at rest. However, when considering the change in $\mathrm{SpO} 2$ during maximal exercise, the $\mathrm{SpO}_{2}$ decreased more in young participants in the unmasked tests, and the $\mathrm{SpO}_{2}$ change with mask use was similar with middle-aged participants. Besides, it was determined that the $\mathrm{SpO}_{2}$ in males compared to females was lower both at rest and after exercise in masked and unmasked tests.

While some studies on heart rate variability with mask use indicated that mask use had no effect on heart rate [21, 23, 24], Li et al. reported that the use of N95 affected heart rate variability [25]. In our study, the $\mathrm{HR}_{\text {peak }}$ was not different in the masked and unmasked test in females; it was found to be lower in males with mask use. Also, the use of masks for both young and middle-aged participants reduced $\mathrm{HR}_{\text {peak }}$. We believe that this difference is due to the type of mask used and different exercise intensities.

Umutlu et al. stated that the use of surgical face masks in the long term may lead to chronic adaptations that negatively affect cardiac functions. Increased respiratory resistance with prolonged inspiratory activity caused by the surgical mask during exercise impairs intrathoracic pressure and causes an increase in stroke volume [26]. In our study, the increase in SBP due to the increase in stroke volume with the use of mask was higher than the test without mask. Especially in young people, $\Delta \mathrm{SBP}$ was higher in the masked test.

Our study had some limitations. Because of the type of gas analyzer device used, the $\mathrm{CO}_{2}$ level could not be measured in the study. The wide range of the age groups could have revealed the effects of the mask better. In addition, measurements during maximal exercise made it difficult to study's adapt the findings to daily life.

\section{Conclusion}

Consequentially, mask use affected respiratory gas exchange parameters both by age and gender. The hemodynamic responses were not affected by gender; on the other hand, age was found to have a various and significant effect on hemodynamic responses. Increased age and male gender affected more to the decrease in maximal exercise capacity with mask use. Due to the importance of adapting masks to daily life, we believe that the effects of mask use according to different age groups and gender during physical activity of different intensity, moderate or mild, will be an important question in further studies.

Acknowledgements The authors thank Sinan Bagcaci, MD of Physical Therapy and Rehabilitation, for the contribution to the development and achievement of this research.

Author contribution All authors contributed to the study conception and design. Sevgi Ozalevli contributed to study design and drafted the manuscript; Busra Alkan made data collection, contributed to design, revisions, and analysis; Ozlem Akkoyun Sert contributed to obtaining permissions and made critical revisions. All the authors contributed to the interpretation of the results and the proof reading of the manuscript.

Data availability Data available upon reasonable request.

\section{Declarations}

Ethics approval This study was performed in line with the principles of the 1964 Helsinki Declaration. Approval was granted by the Ethics Committee of KTO Karatay University (approval number: 2020/027, approval date: 17/07/2020).

Consent to participate Written informed consent was obtained from all individual participants included in the study.

Conflict of interest The authors declare no competing interests.

\section{References}

1. European Centre for Disease Prevention and Control (2021) Using face masks in the community: first update (Effectiveness in reducing transmission of COVID-19 Key messages). ECDC 1-6 
2. Shurlock J, Muniz-Pardos B, Tucker R et al (2021) Recommendations for face coverings while exercising during the COVID19 pandemic. Sport Med - open 7:19. https://doi.org/10.1186/ s40798-021-00309-7

3. Should people wear a face mask during exercise: what should clinicians advise? BJSM blog - social media's leading SEM voice [Internet]. [cited $2020 \mathrm{Jul}$ 30]. https://blogs.bmj.com/bjsm/2020/ 06/12/\%0Ashould-people-wear-a-face-mask-during-exercisewhat-should-clinicians-a\%0Advise/

4. Roberge RJ, Coca A, Williams WJ et al (2010) Physiological impact of the $\mathrm{n} 95$ filtering facepiece respirator on healthcare workers. Respir Care 55:569-577

5. Melnikov VN, Divert VE, Komlyagina TG, et al (2017) Baseline values of cardiovascular and respiratory parameters predict response to acute hypoxia in young healthy men. Physiol Res 66:467-479. https://doi.org/10.33549/physiolres.933328

6. Islam M, Rahman M, De A (2020) Exercising with face mask during the pandemic: a qualitative analysis. Saudi J Sport Med 20:59. https://doi.org/10.4103/sjsm.sjsm_37_20

7. Betik AC, Hepple RT (2008) Determinants of VO2 max decline with aging: an integrated perspective. Appl Physiol Nutr Metab 33:130-140. https://doi.org/10.1139/H07-174

8. Joyner MJ (1993) Physiological limiting factors and distance running: influence of gender and age on record performances. Exerc Sport Sci Rev 21:103-133. https://doi.org/10.1249/ 00003677-199301000-00004

9. Perreault L, Lavely JM, Kittelson JM, Horton TJ (2004) Gender differences in lipoprotein lipase activity after acute exercise. Obes Res 12:241-249. https://doi.org/10.1038/oby.2004.31

10. Riddell MC, Partington SL, Stupka N et al (2003) Substrate Utilization during exercise performed with and without glucose ingestion in female and male endurance-trained athletes. Int J Sport Nutr Exerc Metab 13:407-421. https://doi.org/10.1123/ijsnem. 13.4.407

11. Navalta JW, Montes J, Tanner EA et al (2018) Sex and age differences in trail half marathon running. Int J Exerc Sci 11:281-289

12. Ilhan N, Kamanli A, Ozmerdivenli R, Ilhan N (2004) Variable effects of exercise intensity on reduced glutathione, thiobarbituric acid reactive substance levels, and glucose concentration. Arch Med Res 35:294-300. https://doi.org/10.1016/j.arcmed.2004.03. 006

13. Wise P, Myers H (2002) Gender role expectation of pain: relationship to experimental pain perception. Pain 96:335-342

14. Motoyama Y, Joel G, Pereira P et al (2016) Airflow-restricting mask reduces acute performance in resistance exercise. Sports 4:46. https://doi.org/10.3390/sports 4040046

15. Martin E, Stefan O, Reinhold K (2021) Effects of wearing face masks under moderate physical effort. medRxiv. https://doi.org/ 10.1101/2021.03.18.21253539
16. Bruce R, Kusumi F, Hosmer D (1974) Maximal functional oxygen aerobic intake and nomographic assessment of impairment in cardiovascular disease. Fundam Clin Cardiol 88:372-379

17. Jenkins LA, Mauger AR, Hopker JG (2017) Age differences in physiological responses to self-paced and incremental V' O 2 max testing. Eur J Appl Physiol 117:159-170. https://doi.org/10.1007/ s00421-016-3508-6

18. Hayran M, Hayran M (2011) Sağlık Araştırmaları Için Temel Istatistik. Omega Araştırma, Ankara

19. Hopkins SR, Dominelli PB, Davis CK et al (2021) Face masks and the cardiorespiratory response to physical activity in health and disease. Ann Am Thorac Soc 18:399-407. https://doi.org/10. 1513/AnnalsATS.202008-990CME

20. World Health Organization Advice on the use of masks in the context of COVID-19: interim guidance. In: World Heal. Organ. https://www.who.int/publications-

21. Epstein D, Korytny A, Isenberg Y et al (2020) Return to training in the COVID-19 era: the physiological effects of face masks during exercise. Scand J Med Sci Sport 31:70-75. https://doi.org/10. $1111 /$ sms. 13832

22. Shaw K, Butcher S, Ko J et al (2020) Wearing of cloth or disposable surgical face masks has no effect on vigorous exercise performance in healthy individuals. Int J Environ Res Public Health 17:1-9. https://doi.org/10.3390/ijerph17218110

23. Ng HL, Trefz J, Schönfelder M, Wackerhage H (2021) Effect of a taped filter mask on perceived breathlessness, heart rate, lactate and oxygen saturation during a graded exercise test. BMC Sports Sci Med Rehabil. https://doi.org/10.21203/rs.3.rs-654495/v1

24. Ahmadian M, Ghasemi M, Nasrollahi Borujeni N et al (2021) Does wearing a mask while exercising amid COVID-19 pandemic affect hemodynamic and hematologic function among healthy individuals? Implications of mask modality, sex, and exercise intensity. Phys Sportsmed 00:1-12. https://doi.org/10. 1080/00913847.2021.1922947

25. Li Y, Tokura H, Guo YP et al (2005) Effects of wearing N95 and surgical facemasks on heart rate, thermal stress and subjective sensations. Int Arch Occup Environ Health 78:501-509. https:// doi.org/10.1007/s00420-004-0584-4

26. Umutlu G, Acar N, Sinar D, Akarsu G, Güven E Yİ (2021) COVID-19 and physical activity in sedentary individuals: differences in metabolic, cardiovascular, and respiratory responses during aerobic exercise performed with and without a surgical face masks. J Sports Med Phys Fitness Apr 22. https://doi.org/10. 23736/S0022-4707.21.12313-8

Publisher's Note Springer Nature remains neutral with regard to jurisdictional claims in published maps and institutional affiliations. 